http://dx.doi.org/10.21707/gs.v11.n02a08

\title{
Potencial de Citotoxicidade e mutagenicidade das Águas do Rio Jaru, Estado de Rondônia, Em CÉlulas de AlLiUm CEPA
}

\section{Manoelina lacerda Corrêa de Faria ${ }^{1 *}$, Fábio Medeiros da Costa ${ }^{2}$, Francisco Carlos da Silva ${ }^{3}$, Rosa Maria do Vale Bosso.}

${ }^{1}$ Bolsista de Iniciação Cientifica/CEULJI ULBRA - PIBIC.

${ }^{2}$ Oikos Consultoria e Projetos. Porto Velho, Brasil.

${ }^{3}$ Docente do Centro Universitário Luterano de Ji-Paraná - CEULJI/ULBRA, Ji-paraná-RO, Brasil.

${ }^{4}$ Docente do Instituto Tocantinense Presidente Antônio Carlos - ITPAC, Araguaina -TO, Brasil.

* Autor para correspondência: manoelinafaria@gmail.com

Recebido em 13 de junho de 2016. Aceito em 22 de junho de 2016. Publicado em 29 de julho de 2017.

REsumo - O presente estudo teve como objetivo avaliar o potencial mutagênico e citotóxico por meio da análise das células da raiz de Allium cepa expostas a amostras de águas superficiais do rio Jaru, município de Jaru, Estado de Rondônia. As amostras foram obtidas nos períodos de seca, agosto de 2011 e chuvoso, fevereiro de 2012 em três pontos distintos, sendo o P1 localizado na bomba de captação de águas da CAERD (Companhia de Água e Esgoto de Rondônia), o P2 em local de despejo de efluentes laticínios, e o P3 na zona rural à jusante da sede do município. Bioensaios com bulbos de cebola expostos a água de cada ponto foram conduzidos, comparando-se com o controle negativo que levou apenas água destilada. Em seguida as amostras dos bulbos passaram por tratamentos e cortes histológicos nas regiões dos meristemas apicais da raiz para avaliar o índice de crescimento, o índice mitótico e índice de micronúcleo. No período de seca com relação ao crescimento das raízes foi observada uma diferença estatisticamente significante para $\mathrm{P} 1(\mathrm{P}<0,05)$ e $\mathrm{P} 2(\mathrm{P}<0,01)$ em relação ao controle negativo. Já no período chuvoso não houve diferença estatística. Quanto às análises de índice mitótico, não foi constatada diferença significante em nenhuma das estações analisadas. Já a análise de mutagenicidade mostrou diferenças significantes em P2 (P<0,05) quando comparado ao grupo controle na estação seca. Com base nesses resultados é possível concluir que houve maior interferência de agentes genotóxicos no ponto onde efluentes de laticínios são lançados.

Palavras-chave: Biomonitoramento; Mutagênese; Citotóxico.

\section{Cytotoxic and mutagenic potential of the Jaru River (Rondônia State, Brazil) water on $A$ LLiUM CEPA Cells}

Abstract - This study aimed to evaluate the mutagenic and cytotoxic potential of the Jaru River water, by analyzing the root cells of Allium cepa exposed to surface water samples from such river, inthe municipality of Jaru, Rondônia State, Brazil. The samples were obtained during the dry season August 2011, and rainy season, February 2012, in three distinct points: P1 located in the water catchment pump of the Water and Sewage Company of Rondônia (CAERD), P2 in a dairy effluent disposal area, and P3 in the rural area downstream of the headquarters of the municipality. Bioassays were conducted using onion bulbs exposed to waterfrom each point, except for the negative control, which contained only distilled water. Then the samples of bulbs were subjected to treatments and histological sections in the root apical meristems to evaluate the growth, mitotic, and micronucleus rates. During the dry period, regarding the root growth, it was observed a statistically significant difference for P1 $(\mathrm{p}<0.05)$ and P2 $(\mathrm{p}<0.01)$ compared to the negative control. In the rainy season, there was no statistical difference. About the mitotic rate analysis, no significant difference was found in any of the analyzed seasons. The mutagenicity analysis showed significant differences for P2 ( $<<0.05)$ when compared to 
the control group in the dry season. Based on these results, we concluded that there was more interference of genotoxic agents in the area where dairy effluents are disposed.

Keywords: Biomonitoring; Mutagenesis; Cytotoxicity.

Potencial citotóxico y mutagénico de las aguas del Río Jaru, Estado de Rondônia, Brasil, en células de ALLIUM CEPA

RESumen - El objetivo de este estudio fue evaluarel potencial mutagénico y citotóxico de las aguas del Río Jaru, mediante elanálisis de células de las raíces de Allium cepa expuestas a las aguas superficiales del dicho río, localizo en el municipio de Jaru, Estado de Rondônia, Brasil. Las muestras se obtuvieron en períodos de sequía, en agosto de 2011, y lluvioso, en febrero de 2012, en tres puntos distintos: P1, situado enla bomba de captación de agua de la Compañía de Aguay Alcantarilladode Rondônia (CAERD), el P2 consistió en un área de desechode e fluentes lácteos y el P3 se eligió enla zona rural, enlas aguashaciala sede municipal. Se realizaron bioensayos con bulbos de cebolla expuestos al agua de cada uno de los puntos elegidos, con excepción del control negativo que contenía solo agua destilada. A continuación, las muestras de bulbos de cebolla se sometieron a tratamientos y secciones histológica en los meristemos apicales de la raíz para la evaluación el índice de crecimiento, el índice mitótico y el de micronúcleos.En cuanto al crecimiento de laraíz, durante el período de sequía, se observó una diferencia estadísticamente significativa para el P1 $(p<0,05)$ y para el P2 $(p<0,01)$ en comparación con el control negativo. En la estaciónlluviosa no hubo diferencia estadística. Em cuanto al análisis del índice mitótico, no se encontraron diferencias significativas en ninguna de las estaciones analizadas. Sin embargo, en la estación de sequía, elanálisis de mutagenicidad mostró diferencias significativas para el P2 $(\mathrm{p}<0,05)$ en comparación con el grupo control. Basado en estos resultados se concluye que hubo más interferencia de los agentes genotóxicos en el áreadedesecho de efluentes lácteos.

Palavras clave: Biomonitoreo; MutagÉnesis; Citotoxicidad.

\section{INTRODUÇÃO}

A água é um recurso renovável imprescindível para a vida na terra. A água doce tem uma distribuição muito irregular, tanto no espaço quanto no tempo. Entretanto, as águas renováveis, descargas médias de longo período dos rios do mundo de $43.000 \mathrm{~km}^{3} /$ ano - são muito superiores às demandas totais de água da humanidade da ordem de $6.000 \mathrm{~km}^{3} /$ ano - onde cerca de 70\% é para irrigação, 2\% para consumo industrial e $10 \%$ para consumo doméstico (Rebolsas 2008).

Um dos problemas mais sérios que afetam o meio ambiente é a poluição química de natureza orgânica ou inorgânica, decorrente dos despejos residenciais e industriais. Considera-se como poluição qualquer alteração física, química ou biológica que produza modificação no ciclo biológico normal, interferindo na composição da fauna e da flora do meio. A poluição aquática provoca mudanças nas características das águas, afetando diretamente os seres que dela dependem (Aguiar et al. 2002).

Atividades industriais, urbanas ou rurais dependem da disponibilidade de grandes volumes de água, no entanto, grande parte desse volume retorna a sua fonte de origem com alterações significativas, carreando compostos de alta complexidade. Na indústria a água é utilizada para os mais diversos fins, como, ser incorporada ao produto, limpeza de máquinas, tubulações e pisos, nos sistemas de resfriamento, na geração de vapor, esgoto sanitário dos funcionários, entre outros (Begnini e Ribeiro 2014).

Considerando dados da PNSB (IBGE, 2008), estima-se que são lançadas em corpos d'água cargas de esgotos 
domésticos na ordem de 5,5 mil t DBO5/dia e que apenas 28,5\% das cidades brasileiras realizam o tratamento de esgoto. Este lançamento indevido de efluentes domésticos nos corpos hídricos naturais é responsável pela instalação de processos poluidores fortemente prejudiciais aos sistemas aquáticos, que comprometem os diversos usos dos quais este recurso se destina (Milen 2014; Von Sperling 1997).

Os agentes químicos introduzidos no ambiente podem conduzir a possíveis alterações genéticas nos organismos, essa é uma das principais razões que promoveram o desenvolvimento de métodos para avaliar a genotoxicidade dos produtos químicos. Um estudo internacional colaborativo sobre o uso de bioensaios com plantas para biomonitoramento da genotoxicidade de poluentes ambientais foi iniciado e organizado por organismos mundiais como o Programa Internacional de Segurança Química (IPCS), o Programa Ambiental das Nações Unidas (PNUMA) e da Organização Mundial da Saúde (OMS). Desde então, o objetivo foi de colocar em prática a aplicabilidade de bioensaios, pelos quais podem ser verificadas alterações cromossômicas, anomalias mitóticas e presença de micronúcleos. Estes ensaios de toxicidade constituem uma forma de biomonitoramento ativo, pois neles são utilizados organismos definidos como indivíduos padronizados e cultivados em laboratório, podendo fornecer indicações sobre as condições de um ecossistema frente à presença de impacto ambiental (Raya-Rodriguez, 2000). Esses ensaios fundamentam-se na exposição dos organismos-teste a várias concentrações de uma ou mais substâncias, ou fatores ambientais, durante um determinado período de tempo (GherardiGoldstein et al., 1990; Souza et al. 2013).

Dentre as plantas superiores utilizadas como organismos-teste para detecção de substâncias genotóxicas no ambiente podemos citar algumas das mais empregadas nestes estudos, como Tradescantia pallida (ose) D.R.Hunt 1975 (Commelinales, Commelinaceae), Arabidopsisthaliana Thal 1577 (Brassicales, Brassicaceae), Hordeumvulgare Linnaeus 1753 (Poales, Poacea), Pisumsativum Linnaeus 1753 (Fabales, Fabaceae), Crepiscapillaris Linnaeus 1753 Wallroth 1840 (Asterales, Asteraceae), Vicia faba Linnaeus 1753 (Fabales, Fabaceae), Zeamays Linnaeus 1753 (Poales, Poaceae) e Allium cepa Linnaeus 1753 (Asparagales, Alliaceae).

Allium cepa é um dos testes mais difundidos para análise de toxicidade em água de rios, destacando-se pela sua eficiente cinética de proliferação, crescimento rápido de suas raízes, grande número de células em divisão, sua alta tolerância a diferentes condições de cultivo, disponibilidade durante o ano todo, fácil manuseio, possui cromossomos em número reduzido e de grande tamanho (Fiskesjö 1985; Grant 1994) e também seu baixo custo (Leme \& Marin-Morales 2009).

São várias classes de contaminantes que podem ser detectados pela sensibilidade do teste com $A$. cepa, como metais pesados, esgotos domésticos e industriais, extratos de aterros sanitários e amostras de água de rios e lagos, cujas soluções englobam uma mistura complexa de substâncias de diferentes composições, atestando assim a sensibilidade e eficácia deste bioensaio. Alguns metais pesados, tais como ferro, níquel e cromo, estão entre os contaminantes comumente encontrados nas águas de rios e lagos, atuam como agentes tóxicos, e podem influenciar nas taxas de mitose, induzem aberrações cromossômicas e à formação de micronúcleos em testes realizados com $A$. cepa. Certos metais em solução aquosa podem atravessar a membrana celular ou entrar através de fagocitose ou pinocitose, podendo causar danos à estrutura da molécula de DNA (Barbério 2013).

Os primeiros estudos realizados em raízes de A. cepa foram realizados por Levan (1938) quando investigava a ação tóxica de colchicina. Desde então, inúmeros trabalhos têm usado este protocolo para estimar o perigo ambiental em diversas situações. $\mathrm{O}$ modelo de bioensaio empregando $A$. cepa consiste em um sistema eficiente para análises anatômicas (Crescimento das raízes) e microscópicas (anomalias cromossômicas, índice mitótico e 
formação de micronúcleos) (Egito et al. 2007).

O crescimento das raízes e índice mitótico são parâmetros que permitem avaliar a citotoxicidade do substrato testado. $\mathrm{O}$ índice mitótico é um parâmetro que permite estimar a frequência com que as células estão se dividindo, isto prediz o comportamento do crescimento da raiz, que é conduzida pela frequência de divisão celular no tecido, e isso tem sido correlacionado com um aumento das concentrações de metais tóxicos tais como o cromo e o cádmio (Barbério 2011; Fiskesjö 1993).

Já a observação a nível celular da presença de micronúcleos em células meristemáticas de $A$. cepa indica mutagenicidade. A indução de micronúcleos em meristemas radiculares de $A$. cepa ou em qualquer célula de qualquer outro organismo é a manifestação de danos cromossômicos e perturbação do processo mitótico. O micronúcleo é formado pelo desenvolvimento de uma nova membrana que envolve um pedaço da cromatina que falhou ao passar para ambos os polos durante a anáfase da mitose. Isso pode acontecer a partir de uma disjunção anómala de cromossomos devido a anormalidades do fuso ou ruptura de cromossomos, resultando na formação de fragmentos acêntricos, cromossomos dicêntricos e pontes de cromatina. Assim, a indução de micronúcleos pode sugerir que o poluente ambiental ou é um inibidor do fuso ou clastogênico (Barbério 2011; Fiskesjö 1993).

Desse modo, o estudo aqui aplicado tem por objetivo, avaliar o potencial mutagênico e citotóxico por meio da análise das células da raiz de $A$. cepa expostas a amostras de águas superficiais do rio Jaru, município de Jaru, Estado de Rondônia.

\section{Material e mÉtodos}

As amostras para análise foram coletadas por sazonalidade no período de seca (agosto) do ano de 2011 e no período chuvoso (fevereiro) de 2012, em três pontos distintos ao longo do Rio Jaru, localizado na cidade de Jaru, no estado de Rondônia, Brasil. O primeiro ponto (P1) faz referência ao local (10²6’47.26”S; 62²7’55.02”O) onde a CAERD (Companhia de águas e esgotos do Estado de Rondônia) capta água para tratamento e posterior distribuição à população. Neste mesmo local também são lançados efluentes urbanos não tratados de moradores

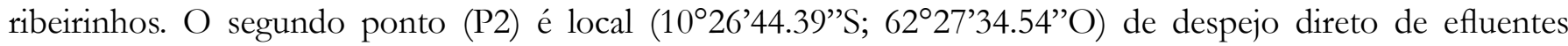
agroindustriais de laticínios e, finalmente, o terceiro (P3) em um ponto localizado (10²2’5.64”S; 62²3’0.60”O) após o rio percorrer toda a extensão da zona urbana e parte rural do município (Figura 1).

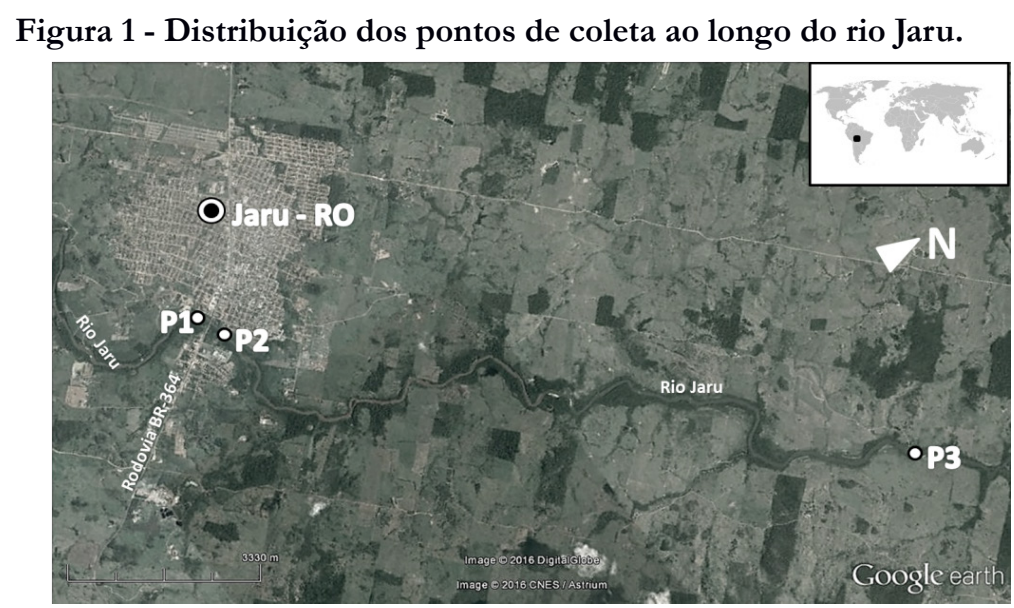

Fonte: Google Earth. 
Em cada ponto foram coletadas amostras de águas superficiais, utilizando-se frascos de vidro com capacidade para dois litros cada. Esses frascos foram devidamente esterilizados e após a captação da água nos pontos anteriormente apresentados, as respectivas amostras foram armazenadas e resfriadas a temperaturas variáveis entre $2^{\circ}$ e $4^{\circ} \mathrm{C}$, conforme metodologia de Fiskesjo (1985).

Foram utilizados bulbos da espécie $A$. cepa, adquiridos comercialmente e de mesma procedência. Os mesmos foram postos a germinar sobre a superfície das amostras de águas coletadas, utilizando 10 bulbos por teste. Para comparação um controle negativo também com bulbos de $A$. cepa foi mantido nas mesmas condições, porém, utilizando-se água destilada. Após 72 horas de crescimento, as raízes foram coletadas, armazenadas em tubos plásticos de 1,5ml de capacidade e fixadas em metanol e ácido acético (proporção 3:1, respectivamente), onde permaneceram por 12 horas.

Para os preparos histológicos das amostras utilizou-se a técnica descrita por Fiskesjo (1985) com adaptações. O processo foi iniciado com a devida lavagem das raízes de $A$. cepa em água destilada, seguida de hidrólise com $\mathrm{HCl} 1 \mathrm{~N}$, por oito minutos em banho-maria a $60^{\circ} \mathrm{C}$. Na sequência, os tubos plásticos foram resfriados em água corrente e uma segunda lavagem dessas raízes em água destilada foi realizada. Os meristemas da parte apical das raízes foram cortados e colocados sobre lâminas que receberam cobertura com lamínula que depois é removida.

Em seguida o material recebeu coloração por meio do kit panótico rápido, conforme descrito por Meneguetti et al. (2011) na sequência dos seguintes compostos: triarilmetano 0,1\%, xantenos $0,1 \%$ e tiazinas 0,1\%. As lâminas foram submersas por um segundo, durante dez vezes em cada solução de coloração, na sequência citada anteriormente.

Após a coloração, as lâminas passaram pela etapa de secagem de 12 horas e finalizadas com a fixação de lamínulas com aplicação de entelan (Fiskesjo 1985).

$\mathrm{Na}$ análise de citotoxicidade as radículas foram medidas 7-8 dias após serem postas para germinar e o índice mitótico foi avaliado na leitura das lâminas ao microscópio óptico. Para a análise de mutagenicidade foi também utilizado microscópio óptico, pelo qual investigou-se a ocorrência de micronúcleos em 2.000 células contadas por bulbo.

O número médio de células em divisão mitótica e o de células com presença de micronúcleos foram analisados pelo teste ANOVA, seguida pelo teste de Tukey, efetuando-se a comparação das médias dos diversos pontos amostrados com o controle negativo com o auxílio do programa Prism ${ }^{\circledR}$ versão 5.0 (GraphPad Software Incorporation2007).

\section{RESUltados E Discussão}

\section{Análise de Citotoxicidade}

Na Figura 2 ( a e b) são apresentadas as médias do comprimento da raiz de $A$. cepa por ponto de coleta e controle negativo nas estações seca de 2011 e chuvosa de 2012. O P2 durante a estação seca obteve o menor índice de crescimento, $\operatorname{com} 2,09 \mathrm{~cm}$, seguido pelo $\mathrm{P} 1 \operatorname{com} 3,3 \mathrm{~cm}$. Com relação à análise de citotoxicidade (crescimento), os dados mostraram que houve índice menor de crescimento das raízes na amostra do ponto um (P1) $(p<0,05)$ e ponto dois (P2) $(p<0,01)$, quando comparados com o controle negativo para a estação seca. Já na estação chuvosa, as variações de crescimento foram entre 2,3 a $4 \mathrm{~cm}$, porém, não foram diferentes 
estatisticamente.

Figura 2 - Índice de crescimento das raízes dos bulbos em relação ao grupo controle na A) estação seca, agosto de 2011 e na B) estação chuvosa, fevereiro de 2012. ** $\mathrm{p}<0,01 *_{\mathrm{p}}<0,05$ (ANOVA, teste de Tukey).

A

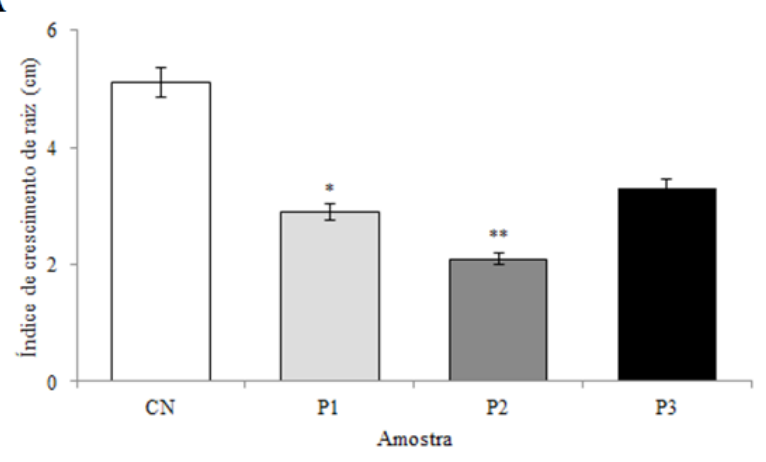

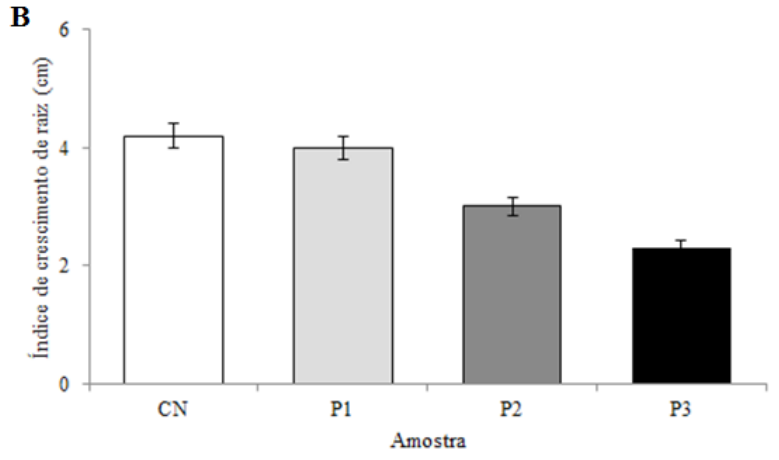

Roa et al. (2012) observaram em testes de citotoxicidade de efluentes industriais de branqueamento de celulose, uma interferência no crescimento das raízes de A. cepa. Da mesma forma Jardim (2004) em estudo realizado no Rio Corumbataí na cidade de Rio claro, estado de São Paulo, em amostras coletadas na estação seca, constatou efeitos citotóxicos com a diminuição no crescimento das raízes quando comparado ao controle negativo. Estes efeitos citotóxicos foram relatados por Fiskesjö (1993) que obteve resultados similares em pontos coletados em um corpo d'água à jusante do despejo de efluentes industriais, onde se observa a ação de interferentes. Oliveira et al. (2012) em estudo realizado no Rio dos Sinos (Rio Grande do Sul -RS) mostraram a ocorrência de citoxicidade no período de estiagem (seca). Estes estudos sugerem uma maior concentração de interferentes no ciclo celularnos pontos e períodos analisados. Todos os autores acima citados utilizaram bulbos de $A$. cepa como organismo teste.

Já na estação chuvosa, Oliveira et al. (2012) que, em testes realizados no Rio dos Sinos (Rio Grande do Sul RS) não encontraram diferença significante. Cuchiara et al. (2012) em análises das águas do Arroio Padre Doutor (RS), trabalhando com sementes de $A$. cepa, também não obtiveram resultado de interferência no crescimento das raízes. Esses resultados sugerem uma maior diluição de compostos interferentes, devido a maior quantidade fluviométrica neste período.

$\mathrm{Na}$ Figura 3 ( a e b) estão expostas as médias do índice mitótico em relação ao grupo controle (Figura 4a), nas quais é possível observar que o número de células em mitose (Figura 4b) variou de 125 a 150 / 2.000 na estação seca e 124 a 190/2.000 na estação chuvosa, entre os pontos analisados. Entretanto, não houve diferenças estatisticamente significantes para os pontos e os controles negativos em ambas as estações analisadas.

Figura 3 - Médias do índice mitótico em relação ao grupo controle (CN) A) na estação seca, agosto de 2011 e B) na estação chuvosa, fevereiro de 2012.
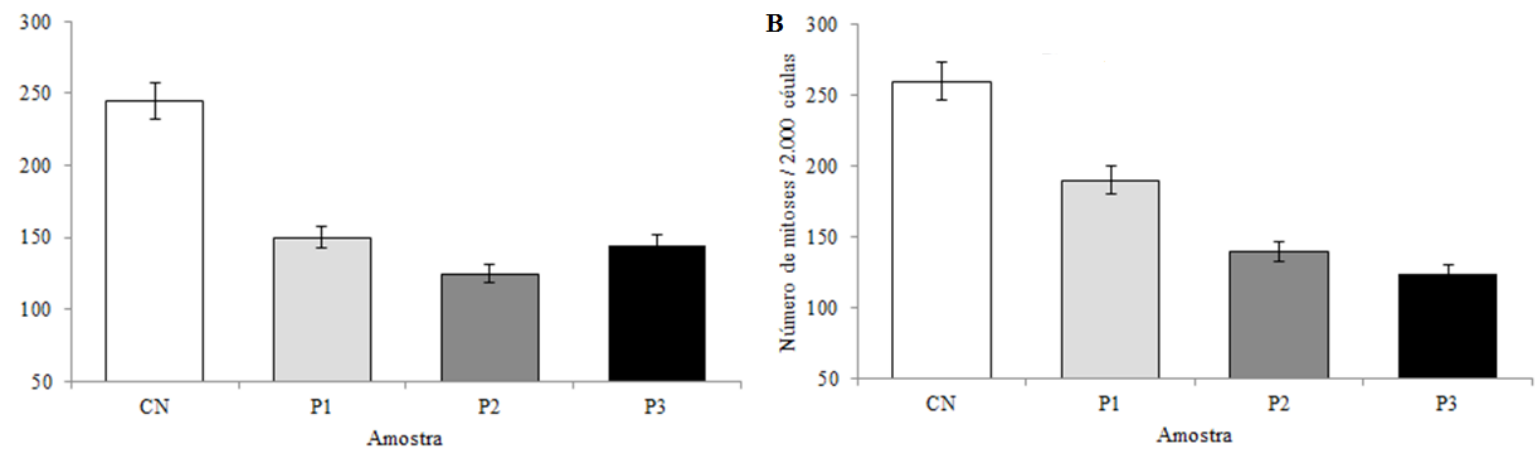
Esses dados estão de acordo com os resultados obtidos por Ferreira et al. (2012), os quais não encontraram citotoxicidade por meio da análise de índice mitótico nas águas de dois ribeirões no estado do Paraná. Oliveira et at. (2011) em estudo realizado no rio Paraíba do Sul (SP) constataram que o índice mitótico não mostrou diferença significante quando comparado ao grupo controle. Ambos, os autores utilizaram como bioindicador bulbos de $A$. cepa.

Associando as alterações no índice mitótico e crescimento das raízes, este estudo mostrou uma interferência no ciclo celular indicando a presença de compostos tóxicos na água, uma vez que tais parâmetros permitem estimar a citotoxicidade (Marcano et al. 2004; Odeigah et al. 1997).

Figura 4 - A) Células interfásicas de meristema apical de raízes de Allium cepa, obtidas de amostra do grupo controle (CN).

B) Células de meristema apical de raízes de Allium cepa em divisão mitótica (setas brancas) obtida de amostra do P1.

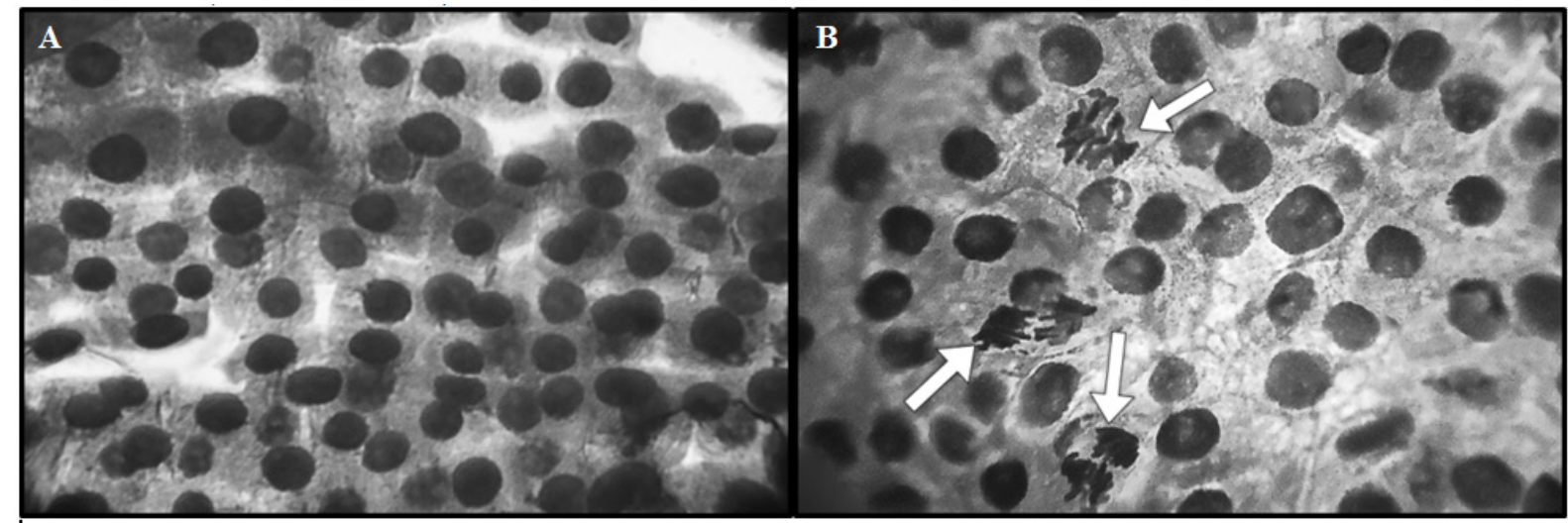

Fonte: os autores

\section{Análise de Mutagenicidade}

Com base nos resultados das análises de micronúcleo no período de seca (Figura 5) é possível identificar potencial mutagênico no ponto de despejo de efluentes laticínios (P2) quando comparado ao controle negativo. Em P2 o índice de micronúcleos (Figura 6) foi de 5,2 / 2.000 células, sendo este significativo (P<0,05). Já em P1 e P3 os índices foram respectivamente, 4,4 e 4 / 2.000 células, porém, não foram encontradas diferentes significativas em relação ao controle negativo. $\mathrm{Na}$ estação chuvosa os índices variaram de 1,7 a 2,65 / 2.000 células entre os pontos amostrados (Figura 7), no entanto, não foram divergentes do controle.

Figura 5 - Índice de micronúcleos em Allium cepa por ponto de coleta em relação ao controle negativo (CN) na estação seca, agosto de 2011. * ${ }^{*}<0,05$ (ANOVA, teste de Tukey).

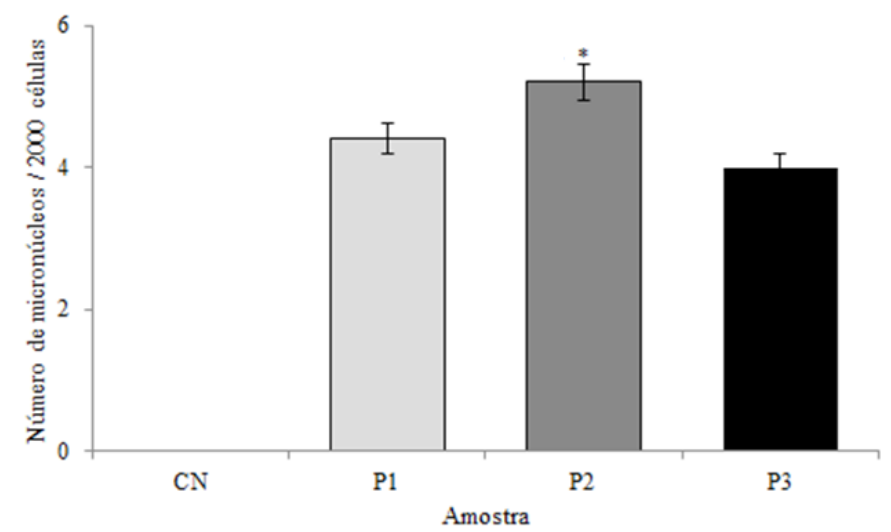

Figura 6 - Células de meristema apical de raízes de Allium cepa com formação de micronúcleos (setas brancas) obtida de 
amostra de P2. Fonte: os autores.

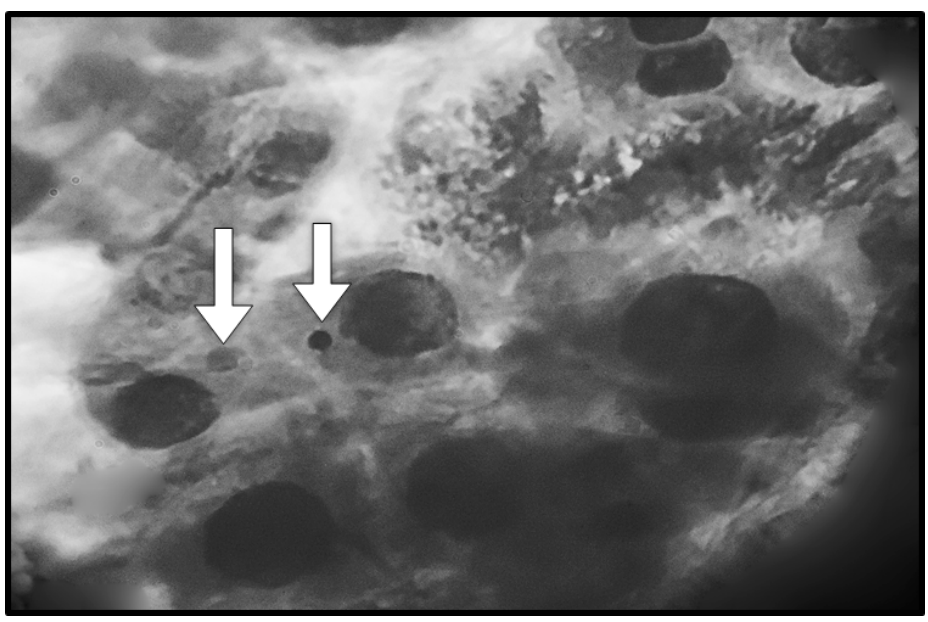

Resultado similar foi relatado por Oliveira et al. (2012) em análise das águas do Rio Sinos (RS) utilizando bulbos de A. cepa. Conforme estudos realizados por Bianchiet al. (2011) em testes com águas do rio Monjolinho, estado de São Paulo, utilizando sementes de $A$. cepa como organismo teste no período caracterizado por maior estiagem pluviométrica, encontraram valores significativos quanto a ocorrência de micronúcleos. Caritá e Marin-Morales (2008) em estudos com sementes de $A$. cepa utilizando amostras de efluentes têxteis, foi possível detectar quebras cromossômicas induzidas por compostos oriundos destes efluentes. Um aumento da presença de micronúcleo foi observado por Radic et al. (2010) em testes realizados em pontos a jusante do despejo de efluentes de indústrias no rio Sava (Croácia) em células meristemáticas de bulbos de $A$. cepa expostos às amostras de água.

Conforme Fiskesjö (1993), Marcano e Del Campo (1995), Türkoglu (2007) micronúcleos são efeitos irreversíveis para a célula, formados por meio de aderências cromossômicas que são sinais comuns da ação tóxica sobre o material genético, podendo promover a morte celular. Assim, constatou-se uma provável influência da sazonalidade na indução de quebras cromossômicas, caracterizando um acúmulo de substâncias tóxicas no período de seca e uma maior ocorrência de tais interferentes no ponto de despejo de efluentes laticínios, o que indica uma ineficiência no processo de tratamento.

Figura 7 - Índice de micronúcleos em Allium cepa por ponto de coleta em relação ao controle negativo (CN) na estação chuvosa (ANOVA, teste de Tukey).

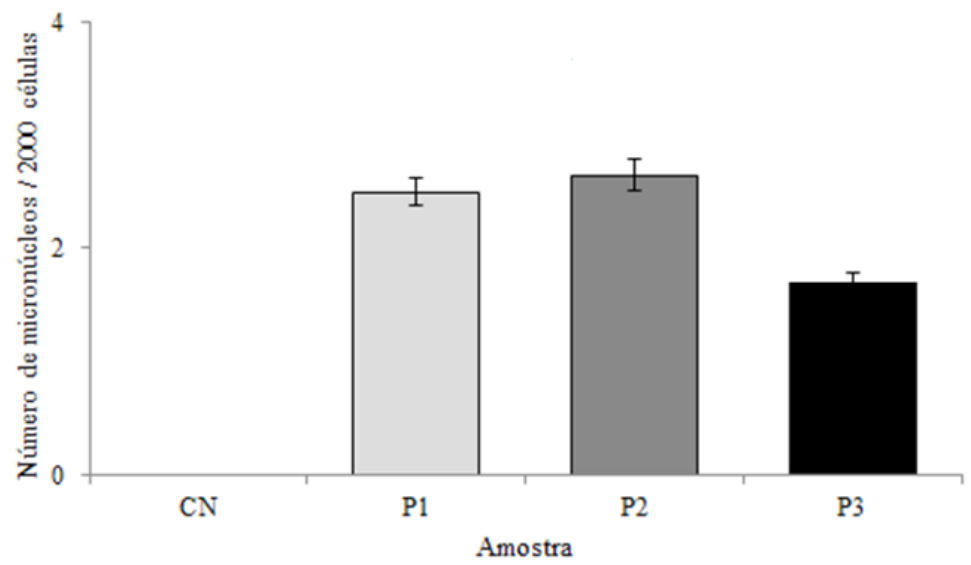

Para as amostras coletadas no período de cheia (Figura 7) não houve diferença estatisticamente significante em relação ao controle negativo no parâmetro do teste de micronúcleos, embora no local de despejo de efluentes 
laticínios tenha sido encontrada maior ocorrência de células micro nucleadas quando comparado aos demais pontos.

Cabral et al. (2007) analisaram a frequência de micronúcleos em $A$. cepa na Barragem Engenho Armando Ribeiro Gonçalves (Rio Grande do Norte) e constataram que os resultados comparados ao grupo controle não indicaram potencial mutagênico. Da mesma forma, Bianchi et al. (2011) em testes realizados com amostras das águas do rio Monjolinho no inverno que é caracterizado pelo grande volume hídrico, obtiveram os mesmos resultados. O período chuvoso por ter uma maior diluição de substâncias tóxicas não apresentou diferença quando comparado ao controle negativo, diferindo do período seco no parâmetro das análises de micronúcleos.

\section{CONCLUSÃo}

De acordo com os resultados, o teste $A$. cepa demonstrou citotoxicidade nas águas do rio Jaru para o ponto um (P1) e ponto dois (P2) em relação ao crescimento das raízes apenas na estação seca, no entanto, este fato não ocorreu para o índice mitótico com significância em nenhuma dos períodos analisados. $\mathrm{Na}$ análise de mutagênese, observou-se resultado significativo para o ponto dois (P2) apenas no período de seca. P2 apresentou citotoxicidade e mutagenicidade, o que indica ineficácia no tratamento dos efluentes ali lançados. Por meio desta pesquisa, observa-se a necessidade de melhoria neste tratamento e a implantação de um biomonitoramento constante nos locais analisados do rio Jaru. Este levantamento pode contribuir para a orientação na tomada de decisões com relação a aplicação de medidas mitigadoras contra poluição ambiental, visando a melhoria da qualidade dos recursos naturais hídricos, visto que, na região amazônica pesquisas de monitoramento da qualidade da água com organismos in vivo ainda são escassas.

\section{Agradecimentos}

Os autores agradecem ao CEULJI/ULBRA pelo apoio na condução dos testes e ao CNPq pela concessão de bolsa de iniciação científica para a primeira autora.

\section{REFERÊNCIAS}

Aguiar, MRMP, Novaes AC, GuarinoAWS. 2002. Remoção de metais pesados de efluentes industriais por alumínios silicatos. Química Nova, São Paulo, v.25, n. 6b, Dec.

Barbério A, Voltolini JC, Mello MLS. 2011. Standardization of bulb and root numbers for the Allium cepa test. Ecotoxicology. Jun. 20(4): 927-935.

Barbério A. 2013. Bioassays with Plants in the Monitoring of Water Quality. In: Water Treatment, 13, InTech, Chapters published January 16.

Begnini BC e Ribeiro HB. 2014. Plano para redução de carga poluidora em indústria de laticínios. Saúde e Meio Ambiente, v. 3, n. 1, p. 19-30, jan./jun. 
Bianchi J, Espindola ELG, Marin-Morales MA. 2011.Genotoxicity and mutagenicity of water samples from the Monjolinho River (Brazil) after receiving untreated effluents; Ecotoxicology and Environmental Safety 74; p 826-833.

Brasil. Lei $\mathrm{n}^{\circ}$ 7.802, de 11 de julho de 1989. In: Legislação federal de agrotóxicos e afins. Brasília (DF): Ministério da Agricultura e do Abastecimento; 1998. p. 7-13

Cabral TM, PanossoRF, Medeiros SRB. 2007.Avaliação da genotoxicidade das águas superficiais da barragem Engenheiro Armando Riebrio Gonçalves Assu/RN; Dissertação de Mestrado apresentada ao programa de Pós-graduação em Genética e Biologia Molecular da Universidade Federal do Rio Grande do Norte.

Caritá R \& Marin-Morales MA. 2008. Induction of chromosome aberrations in the Allium cepa test system caused by the exposure of seeds to industrial effluents contaminated with azo dyes; Chemosphere 72; p 722-725.

Cuchiara CC, Borges C S, Bobrowski VL. 2012. Sistema teste de Allium cepa como bioindicador da citogenotoxicidade de cursos d'água; Revista Tecnologia \& Ciência Agropecuária., João Pessoa; v.6, n.1; p.33-38.

Egito LCM, Medeiros MG, De Medeiros SRB, Agnez-Lima LF. 2007. Cytotoxic and genotoxic potential of surface water from the Pitimbu river, northeastern/RN Brazil. Genetics and Molecular Biology30(2): 435441.

Ferreira CF, Frueh AB, Dusman E, Heck MC, Vicentini VEP. 2012.Avaliação da citotoxicidade das águas dos ribeirões Varginha (Califórnia-PR) e Tabatinga (Mandaguari-PR), em Allium cepa L.; SaBios: Revista de Saúde e Biologia, v.7, n.2, p.46-54, mai./ago.

Fiskesjö G. 1993.The Allium cepatest in wastewater monitoring.Environmental Toxicology and Water Quality, v.8, p.291-298.

Fiskesjö G. 1985.The Allium test as a standard in environmental monitoring.Hereditas, v.102, p.99-112.

Gherardi-Goldstein E, Bertoletti E. Zagatto PA. Araujo RPA. \& Ramos MLLC. 1990. Procedimentos para Utilização de Testes de Toxicidade no Controle de Efluentes Líquidos. CETESB, São Paulo.

Google. Google Earth. Versão 7.1.5.1557. Disponível em: https://www.google.com/earth/. Acessoem: 05 jun. 2016. Grant WF. 1994. The present status of higher plant bioassays for detection of environmental mutagens. MutationResearch, v.310, p.175-185.

GraphPad Software Incorporation 2007.User guide.Disponível em: http://www.graphpad.com/guides/prism/7/userguide/index.htm?tips for using prism.htm.Acesso em: 05 ago. 2012.

IBGE. 2008. Pesquisa nacional de saneamento básico 2008.Brasília-DF.

Jardim GM, Monteiro RTR. 2004. Estudos ecotoxicológicos da água e do sedimento do Rio Corumbataí 
- SP; Dissertação apresentada á Escola Superior de Agricultura “Luiz de Queiroz” Universidade de São Paulo. Levan A. 1938. The effect of colchicine on root mitosis in Allium. Hereditas, v.24, p. 471- 486.

Leme D M \& Marin-Morales MA. 2009. Allium cepa test in environmental monitoring: A review on its application. Mutation Research, 682: 71-81.

Marcano L, Del Campo A. 1995. Estudio ultraestructural del nucléolo em poblaciones meristemáticas de cebela Allium cepa L. tratadas com inhibitores metabólicos. Ciência, v.3, p.73-82.

Marcano L, Carruyo I, Campo AD, Montiel X. 2004.Cytotoxicity and mode of action of maleic hydrazide in root tips of Allium cepa L.; Environmental Research.; 94:221-226; 2004.

MeneguettiDUO, Da Silva FC, Zan RA, Poletto PO, Ramos LJ. 2011. Adaptação da técnica de micrúcleo em Allium cepa, para futuras análises de mutagenicidade dos rios da região do Vale do Jamari, Rondônia, Amazônia Ocidental; Revista Pesquisa \& Criação - V 10, No 2.

Milen LC. 2014. Tratamento de esgoto doméstico pelo método de escoamento superficial no solo: Uma revisão de literatura. Revista Verde (Pombal - PB - Brasil), v 9, n. 5 , p. 26 - 33, dez.

Odeigah O, NurudeenO, Amund OO. 1997. Genotoxicity of oil field wastewater in Nigeria.Hereditas; 126:161167.

Oliveira JPW, Santos RN, Pibernat CC, Boeira JM. 2012. Genotoxicity and Physical Chemistry Analysis of waters from Sinos River (RS) using Allium cepaand Eichhornia crassipes as bioindicators; BBR - Biochemistry and Biotechnology Reports; v.1 n.1 Jan./Jun., p.15-22.

Oliveira M, VoltoliniL, Cesar J, Barbério A. 2011. Potencial mutagênico dos poluentes na água do rio Paraíba do Sul em Tremembé, SP, Brasil, utilizando o teste Allium cepa; Ambiente \& Água - Na Interdisciplinary Journal of Applied Science; vol. 6, núm. 1; pp. 90-103.

Radic S, Stipanicev D, Vujcic V, Rajcic MM, Sirac S, Pevalek-kozlina B. 2010. The evaluation of surface and wastewater genotoxicity using the Allium cepa test; Science of the Total Environment 408; p 1228-1233.

Rebolsas A. Uso inteligente da água. São Paulo: Escrituras Editora, 2008.

Roa O, YeberMC, VenegasW. 2012. Genotoxicity and toxicity evaluations of ECF cellulose bleaching effluents using the Allium cepaL. Test; Brazilian Journal of Biology., vol. 72, no. 3, p. 471-477.

Souza CC, Padula L, Silva LF, Irazusta SP. 2013. Validação dos Bioensaios de Toxicidade como Adjuvantes no Monitoramento de Efluentes para Descarte. Ecotoxicology and Environmental Contamination., v. 8, n. 2, 01-07 doi: 10.5132/eec.2013.02.001.

Türkoglu S. 2007. Genotoxicity of five food preservatives tested on root tips of Allium cepaL. Mutation Research, v.626, p.4-14.

Von Sperling E. 1997. Qualidade de água. 1.ed. Brasília: ABEAS, 59p. 